\title{
Ácidos orgânicos como extratores de metais pesados fitodisponíveis em solos tratados com lodo de esgoto
}

\author{
Adriana Marlene Moreno Pires ${ }^{(1)}$, Maria Emília Mattiazzo(2) e Ronaldo Severiano Berton ${ }^{(3)}$
}

\begin{abstract}
(1)Embrapa Meio Ambiente, Caixa Postal 69, CEP 13820-000 Jaguariúna, SP. E-mail: adriana@cnpma.embrapa.br (2)Escola Superior de Agricultura Luiz de Queiroz, Dep. de Ciências Exatas, Caixa Postal 9, CEP 13418-900 Piracicaba, SP. E-mail: mmatiazo@esalq.usp.br (3)Instituto Agronômico, Caixa Postal 18, CEP 13001-970 Campinas, SP. E-mail: rsberton@iac.sp.gov.br
\end{abstract}

Resumo - Ainda não foi desenvolvido um método de extração eficiente para estimar teores fitodisponíveis de metais pesados, porque os extratores utilizados não simulam reações semelhantes às que ocorrem próximo às raízes. O objetivo deste trabalho foi avaliar uma solução de ácidos orgânicos rizosféricos como extratora de teores fitodisponíveis de metais pesados presentes em solos tratados com lodo de esgoto. Os solos utilizados foram: Latossolo Amarelo distrófico, Neossolo Quartzarênico e Latossolo Vermelho distrófico, cultivados com plantas de banana, pupunha e café, respectivamente. A avaliação do extrator (solução composta por ácido acético, cítrico, lático e oxálico em concentrações de 1,00, 0,72,0,49 e $0,12 \mathrm{~mol} \mathrm{~L}^{-1}$, respectivamente) foi feita a partir da análise da correlação entre teores de metais pesados $(\mathrm{Cd}, \mathrm{Cr}, \mathrm{Cu}, \mathrm{Ni}, \mathrm{Pb}$ e $\mathrm{Zn})$ extraídos do solo e os teores nas plantas. As correlações foram significativas, indicando a eficiência do extrator para todos os casos estudados. Entre os metais avaliados, as quantidades extraídas de Pb correlacionaram-se melhor com teor fitodisponível nas três situações investigadas.

Termos para indexação: biossólido, elementos traço.

\section{Organic acids as extractors of phytoavailable heavy metals in soils treated with sewage sludge}

\begin{abstract}
An efficient extraction method to estimate concentrations of phytoavailable heavy metals has not been established yet, because the extractors used do not simulate reactions close to the roots. The objective of this work was to evaluate the use of a rhizospheric acid organic solution as an extractor of phytoavailable heavy metal from soils (Oxisols) treated with sewage sludge. Three Oxisols with different textures cultivated with banana, peach palm and coffee were studied. The extractor (solution composed by acetic, citric, lactic and oxalic acids with concentrations of $1.00,0.72,0.49$ and $0.12 \mathrm{~mol} \mathrm{~L}^{-1}$, respectively) evaluation was performed from correlation analyzes between heavy metals $(\mathrm{Cd}, \mathrm{Cr}, \mathrm{Cu}, \mathrm{Ni}, \mathrm{Pb}$ e $\mathrm{Zn})$ concentrations extracted from the soil, and plant tissue concentrations. The correlation was significant, indicating the extractant efficiency in all studied cases. Comparing the studied elements, the $\mathrm{Pb}$ amount extracted correlated better with its phytoavailability on the three situations investigated.
\end{abstract}

Index terms: biosolid, trace elements.

\section{Introdução}

O teor fitodisponível de metais pesados presentes em solos tratados com lodo de esgoto é fundamental na avaliação do risco de entrada desses elementos, potencialmente tóxicos, na cadeia alimentar (Estados Unidos, 1993). Entretanto, ainda não foi estabelecido um método que estime eficientemente teores fitodisponíveis de metais pesados em solos e espécies vegetais diferentes (Mattiazzo et al., 2001). A principal dificuldade na escolha do extrator é a variação de sua eficiência conforme a quantidade e tipo de metal presente no lodo de esgoto, o processo de obtenção do resíduo, o tipo de solo, a presença de outras espécies químicas e a espécie vegetal em questão (Bertoncini, 2002).

Mattiazzo et al. (2001) realizaram uma revisão sobre a eficiência dos extratores utilizados para estimar fitodisponibilidade e concluíram que, com exceção de $\mathrm{Cu}$ e $\mathrm{Zn}$, ainda não existe um extrator que apresente boa correlação com as quantidades de metais absorvidas pelas plantas.

Vários métodos de extração têm sido propostos, envolvendo diferentes tipos de soluções. Soluções neutras, com força iônica similar à do solo, como $0,01 \mathrm{~mol} \mathrm{~L}^{-1} \mathrm{de}$ 
$\mathrm{CaCl}_{2}$ (Ure, 1995), são freqüentemente utilizadas na previsão de teores fitodisponíveis de metais pesados, assim como soluções de ácidos fortes, como $\mathrm{HCl}$ $\left(0,1 \mathrm{~mol} \mathrm{~L}^{-1}\right)$ (Page et al., 1982) e Mehlich 1 (Nelson et al., 1953). Agentes quelantes como DTPA, ou soluções ácidas e quelantes como o Mehlich-3 (Mehlich, 1984) também são utilizados. O DTPA-TEA (pH 7,3), desenvolvido por Lindsay \& Norwell (1978), é o extrator mais utilizado no Estado de São Paulo em estudos de previsão da fitodisponibilidade. Embora esse extrator tenha sido desenvolvido para estimar teores fitodisponíveis de $\mathrm{Cu}, \mathrm{Mn}$ e $\mathrm{Zn}$ em solos alcalinos ou com $\mathrm{pH}$ próximo à neutralidade, ele tem-se mostrado eficiente também para micronutrientes presentes em solos ácidos. Entretanto, a eficiência desse extrator é reduzida quando são considerados metais com maior potencial tóxico, como $\mathrm{Cd}, \mathrm{Cr}$, $\mathrm{Ni}$ e $\mathrm{Pb}$ (Abreu et al., 1995). Nas condições de acidez da maioria dos solos brasileiros, os resultados são pouco conclusivos na previsão da fitodisponibilidade (Andrade \& Mattiazzo, 2000; Oliveira, 2000; Anjos \& Mattiazzo, 2001). As baixas correlações se devem ao fato de que os extratores usados não simulam as reações que ocorrem na rizosfera (Berton, 2000).

Marschner (1995) cita que ácidos orgânicos de baixo peso molecular presentes na rizosfera são efetivos na solubilização de metais ligados à fração sólida do solo. Dentre os poucos estudos realizados na fitodisponibilização de metais pesados presentes em solos tratados com lodo de esgoto que usaram como solução extratora ácidos orgânicos, destacam-se o de Mench \& Martin (1991) e o de Koo (2001). Os primeiros autores observaram que $\mathrm{Cd}, \mathrm{Cu}, \mathrm{Fe}, \mathrm{Mn}$, Ni e $\mathrm{Zn}$ foram solubilizados por exsudatos de raiz de Nicotiana tabacum L., $N$. rustica L. e Zea mays L. A composição química dos exsudatos foi diferente para as três espécies, mas a quantidade de metais extraída foi semelhante quando as espécies foram cultivadas no mesmo solo. Koo (2001) avaliou a influência de ácidos orgânicos na cinética de solubilização de metais pesados presentes em solos tratados com lodo de esgoto e concluiu que o comportamento da solubilização foi semelhante ao da absorção dos metais por plantas cultivadas nestes mesmos solos.

O objetivo deste trabalho foi avaliar uma solução de ácidos orgânicos rizosféricos como extratora de teores fitodisponíveis de metais pesados em solos tratados com lodo de esgoto.

\section{Material e Métodos}

O experimento foi realizado no período de abril a agosto de 2002, no laboratório de Química Ambiental da Esalq/USP.

A composição da solução extratora baseou-se em teores de ácidos orgânicos encontrados na rizosfera de diferentes espécies vegetais cultivadas na presença de lodo de esgoto, segundo Pires (2003), a saber: ácido acético, $43 \%$; cítrico, $31 \%$; lático, $21 \%$ e oxálico, $5 \%$.

Testes preliminares foram realizados por meio de uma avaliação da relação solo:solução, tempo de agitação e concentração da solução extratora com o intuito de determinar o melhor procedimento de extração. A relação solo:solução foi escolhida visando à obtenção de maiores concentrações de metais pesados no extrato, haja vista as limitações que ocorrem na determinação analítica em relação à ocorrência de concentrações de metais pesados abaixo dos limites de detecção dos instrumentos utilizados. O tempo de agitação foi escolhido com base no tempo necessário para que o equilíbrio entre os metais em solução e os presentes na fase sólida fosse estabelecido.

Quanto à concentração de ácidos orgânicos da solução extratora, primeiramente testaram-se concentrações próximas às obtidas por Pires (2003). Entretanto, os extratos obtidos utilizando estas concentrações apresentavam, na maioria dos casos, teores de metais pesados abaixo dos limites de detecção do instrumento analítico utilizado. Portanto, adotou-se uma concentração de ácidos orgânicos maior do que a encontrada na rizosfera. Para tal, considerou-se que a concentração de ácido acético seria igual a $1 \mathrm{~mol} \mathrm{~L}^{-1}$. Foram calculadas as concentrações dos demais ácidos, respeitando-se a proporção encontrada por Pires (2003), resultando na seguinte composição da solução de ácidos orgânicos: acético (43\%, 1,00 mol L-1), cítrico $\left(31 \%, 0,72 \mathrm{~mol} \mathrm{~L}^{-1}\right)$, lático $\left(21 \%, 0,49 \mathrm{~mol} \mathrm{~L}^{-1}\right)$ e oxálico $\left(5 \%, 0,12 \mathrm{~mol} \mathrm{~L}^{-1}\right)$. A solução foi preparada com água deionizada contendo $0,4 \%$ de clorofórmio para inibir a atividade microbiana.

Com base nos resultados dos testes preliminares, o seguinte procedimento analítico foi adotado: adicionaram-se $20 \mathrm{~mL}$ de solução extratora a $5 \mathrm{~g}$ de amostra de terra tratada com lodo de esgoto, agitou-se a suspensão por seis horas (agitador horizontal Innova 2,100-250 rpm), filtrou-se o extrato usando papel de filtro Whatman $\mathrm{n}-1$, e quantificou-se os metais $\mathrm{Cd}, \mathrm{Cr}$, $\mathrm{Cu}, \mathrm{Ni}, \mathrm{Pb}$ e $\mathrm{Zn}$ no extrato em espectrofotômetro de emissão atômica por indução de plasma (ICP-AES). 
Foram utilizadas amostras de três experimentos desenvolvidos em diferentes tipos de solos, tratados com diferentes tipos de lodo de esgoto e cultivados com diferentes espécies vegetais. A escolha de experimentos com características variáveis é importante para testar a eficiência do extrator em situações diversas.

O solo foi amostrado no período compreendido entre a adição de lodo de esgoto e o plantio para realização da remoção de metais pesados pela solução de ácidos orgânicos. Amostras da folha diagnóstico de cada espécie vegetal foram utilizadas para avaliação dos teores de metais pesados no tecido vegetal. As amostras foram secadas em estufa $\left(60^{\circ} \mathrm{C}\right)$ e moídas (malha de 2 mesh) para análise. O método consistiu na digestão nítricoperclórica das amostras em microondas (EPA 3052), seguida da quantificação dos metais no extrato obtido. A determinação dos metais $\mathrm{Cd}, \mathrm{Cr}, \mathrm{Cu}, \mathrm{Ni}, \mathrm{Pb}$ e $\mathrm{Zn}$ nos extratos de solo e de planta foi feita por espectrofotometria de emissão atômica por indução de plasma (ICP-AES). Os atributos dos solos e do lodo de esgoto são apresentados nas Tabelas 1 e 2, respectivamente. $\mathrm{O}$ experimento 1 foi realizado no Município de Pariquera-Açu, SP, em Latossolo Amarelo distrófico típico cultivado com bananeira e tratado com lodo de esgoto proveniente da Estação de Tratamento de Esgotos (ETE) de Bichoró, em uma única aplicação, em blocos casualizados, nas doses correspondentes a 0,74, 147 e $294 \mathrm{Mg} \mathrm{ha}^{-1}$ do material sem secar. Amostras de folha diagnóstico (3a folha a partir do ápice, na emissão da inflorescência) foram coletadas dez meses após o plantio. O experimento 2 foi realizado no Município de Ubatuba, SP, em Neossolo Quartzarênico cultivado com pupunheira e tratado com lodo de esgoto proveniente da ETE de Bertioga, SP, em uma única aplicação, em blocos casualizados, nas doses $0,42,84$ e $168 \mathrm{Mg} \mathrm{ha}^{-1}$ do material sem secar. Amostras de folha diagnóstico (folículos centrais de folhas medianas, no verão) foram coletadas 13 meses após o plantio. $\mathrm{O}$ experimento 3 foi realizado no Município de Campinas, SP, em Latossolo Vermelho distrófico cultivado com café e tratado com lodo de esgoto proveniente da ETE de Jundiaí, SP, em uma única aplicação, em blocos casualizados, nas doses 0, 30, 60 e $120 \mathrm{Mg}$ ha $^{-1}$ do material sem secar . Amostras de folha diagnóstico (3o e 4o par de folhas) foram coletadas sete meses após o plantio.

A eficiência do método foi avaliada a partir da análise dos coeficientes de correlação (teste F) entre os teores de metais pesados extraídos dos solos e os teores encontrados nas folhas diagnóstico das culturas estudadas.

\section{Resultados e Discussão}

A concentração de alguns metais pesados na folha encontrava-se abaixo do limite de detecção do instrumento analítico utilizado: $\mathrm{Cd}$ e $\mathrm{Cr}$ nas folhas da bananeira (experimento 1); $\mathrm{Cd}, \mathrm{Cr}$ e $\mathrm{Ni}$ nas folhas de pupunha (experimento 2) e $\mathrm{Cr}$ nas folhas de café (experimento 3). Em algumas repetições, o teor de $\mathrm{Pb}$ também estava abaixo do limite, sendo estas excluídas das correlações.

A eficiência do extrator em avaliar os teores fitodisponíveis de $\mathrm{Cd}, \mathrm{Cu}, \mathrm{Ni}, \mathrm{Pb}$ e $\mathrm{Zn}$ nos experimentos estudados foi constatada pela significância das correlações (Figuras 1, 2 e 3). Ordenando-se de forma decrescente os coeficientes de correlação de cada metal pesado em cada experimento, tem-se: banana: $\mathrm{Pb}>\mathrm{Ni}>\mathrm{Zn}>\mathrm{Cu}$; pupunha: $\mathrm{Pb}>\mathrm{Zn}>\mathrm{Cu}$ e café: $\mathrm{Pb}>\mathrm{Zn}>\mathrm{Cd}>\mathrm{Ni}>\mathrm{Cu}$. Devem-se destacar os altos coeficientes de correlação obtidos em relação ao $\mathrm{Pb}$, Ni e $\mathrm{Cd}$, uma vez que a maioria dos extratores utilizados atualmente tem baixa eficiência em relação a estes metais pesados em função da baixa concentração extraída e limitações analíticas (Anjos \& Mattiazzo, 2001).

$O$ fato de as correlações terem sido significativas nos experimentos avaliados, independentemente do metal pesado, espécie vegetal e tipo de solo considerado, parece ser uma vantagem do método de extração propos-

Tabela 1. Atributos químicos e granulometria dos $\operatorname{solos}^{(1)}$.

\begin{tabular}{|c|c|c|c|c|c|c|c|c|c|c|c|c|}
\hline \multirow[t]{2}{*}{ Experimento } & \multirow[t]{2}{*}{$\begin{array}{c}\mathrm{pH} \\
\left(\mathrm{CaCl}_{2}\right)\end{array}$} & \multirow[t]{2}{*}{$\begin{array}{c}\mathrm{MO} \\
\left(\mathrm{g} \mathrm{dm}^{-3}\right)\end{array}$} & \multirow[t]{2}{*}{$\begin{array}{c}\mathrm{P}_{(\text {(resina) }} \\
\left(\mathrm{mg} \mathrm{dm}^{-3}\right)\end{array}$} & $\mathrm{K}$ & & & & Argila & Silte & $\begin{array}{l}\text { Areia } \\
\text { total }\end{array}$ & $\begin{array}{l}\text { Areia } \\
\text { grossa }\end{array}$ & $\begin{array}{c}\text { Areia } \\
\text { fina }\end{array}$ \\
\hline & & & & \multicolumn{4}{|c|}{$-----\left(\mathrm{mmol}_{\mathrm{c}} \mathrm{dm}^{-3}\right)-----$} & & & $15 \pi$ & & \\
\hline Experimento 1 & 4,1 & 20 & 4 & 0,6 & 9 & 3 & 80 & 372 & 136 & 492 & 239 & 253 \\
\hline Experimento 2 & 4,2 & 28 & 18 & 2,4 & 12 & 3 & 64 & 176 & 223 & 601 & 201 & 400 \\
\hline Experimento 3 & 6,0 & 27 & 174 & 5,3 & 34 & 19 & 28 & 302 & 87 & 611 & 376 & 235 \\
\hline
\end{tabular}

(1) Os atributos químicos e a gronulometria foram determinados conforme Raij \& Quaggio (1983) e Camargo et al. (1986), respectivamente. 
to e deve ser mais investigada. Isto porque a maioria dos extratores utilizados tem sua eficiência alterada de acordo com a variação do local, lodo de esgoto, metal pesado e planta avaliada (Mattiazzo et al., 2001).

Tabela 2. Análise química do lodo de esgoto ${ }^{(1)}$.

\begin{tabular}{lrrr}
\hline Propriedade & Bichoró & Bertioga & Jundiaí \\
\hline $\mathrm{C}$ orgânico $\left(\mathrm{g} \mathrm{kg}^{-1}\right)$ & 307,0 & 232,2 & 302,0 \\
$\mathrm{pH}$ & 10,8 & 8,3 & 10,2 \\
Umidade (\%) & 81,9 & 48,4 & 65,8 \\
Sólidos voláteis (\%) & 50,5 & 54,5 & 51,3 \\
$\mathrm{~N} \mathrm{Kjeldahl}\left(\mathrm{g} \mathrm{kg}^{-1}\right)$ & 36,8 & 16,0 & 34,0 \\
$\mathrm{P}\left(\mathrm{g} \mathrm{kg}^{-1}\right)$ & 23,8 & 7,9 & 12,5 \\
$\mathrm{Ca}\left(\mathrm{g} \mathrm{kg}^{-1}\right)$ & 172,2 & 6,3 & 156,5 \\
$\mathrm{Fe}\left(\mathrm{g} \mathrm{kg}^{-1}\right)$ & 82,5 & 7,6 & 7,6 \\
$\mathrm{Al}\left(\mathrm{g} \mathrm{kg}^{-1}\right)$ & 7,4 & 4,9 & 7,4 \\
$\mathrm{Cd}\left(\mathrm{mg} \mathrm{kg}^{-1}\right)$ & 1,0 & 0,4 & 0,9 \\
$\mathrm{~Pb}\left(\mathrm{mg} \mathrm{kg}^{-1}\right)$ & 61,7 & 12,5 & 45,8 \\
$\mathrm{Cu}\left(\mathrm{mg} \mathrm{kg}^{-1}\right)$ & 160,2 & 28,9 & 98,5 \\
$\mathrm{Cr}\left(\mathrm{mg} \mathrm{kg}^{-1}\right)$ & 61,7 & 17,4 & 41,2 \\
$\mathrm{Ni}\left(\mathrm{mg} \mathrm{kg}^{-1}\right)$ & 24,8 & 8,4 & 18,9 \\
$\mathrm{Zn}\left(\mathrm{mg} \mathrm{kg}^{-1}\right)$ & 559,0 & 112,2 & 478,6 \\
\hline
\end{tabular}

(1)Análises realizadas segundo Eaton et al. (1995); teores com base na matéria seca; material proveniente das estações de tratamento de esgoto dos municípios paulistas de Bichoró, Bertioga e Jundiaí.
Anjos \& Mattiazzo (2001) avaliaram os extratores DTPA-TEA (pH 7,3), HCl 0,1 mol L-1, Mehlich 3 e água régia $\left(\mathrm{HCl}+\mathrm{HNO}_{3}, 3: 1\right)$ para estimar teores fitodisponíveis de $\mathrm{Cu}$ e $\mathrm{Zn}$ em milho cultivado em Latossolos tratados com lodo de esgoto. As correlações obtidas foram significativas para todos os extratores, com exceção do $\mathrm{Cu}$ extraído por $\mathrm{HCl} 0,1 \mathrm{~mol} \mathrm{~L}^{-1}$. Por sua vez, Oliveira (2000) não encontrou correlação significativa de $\mathrm{Cu}$ e $\mathrm{Zn}$ em folhas de cana cultivada em Latossolo tratado com lodo de esgoto e teores desses metais extraídos do solo por $\mathrm{HCl}$ 0,1 mol L-1, Mehlich 3 e DTPATEA. Em comparação com os dados existentes sobre extração de teores de micronutrientes em situações de deficiência, ainda é limitado o conhecimento sobre eficiência de extratores de $\mathrm{Cd}, \mathrm{Cr}$, $\mathrm{Ni}$ e $\mathrm{Pb}$ fitodisponíveis em situações de toxicidade nos solos tratados com lodo de esgoto ou outros resíduos (Ure, 1995).

O caráter complexante dos ácidos orgânicos deve ter contribuído para que o método fosse eficiente em estimar teores fitodisponíveis nos casos estudados. Em estudo sobre avaliação de fitodisponibilidade de Zn, Bataglia \& Raij (1994) citam que o DTPA-TEA foi superior provavelmente por ser um agente complexante,
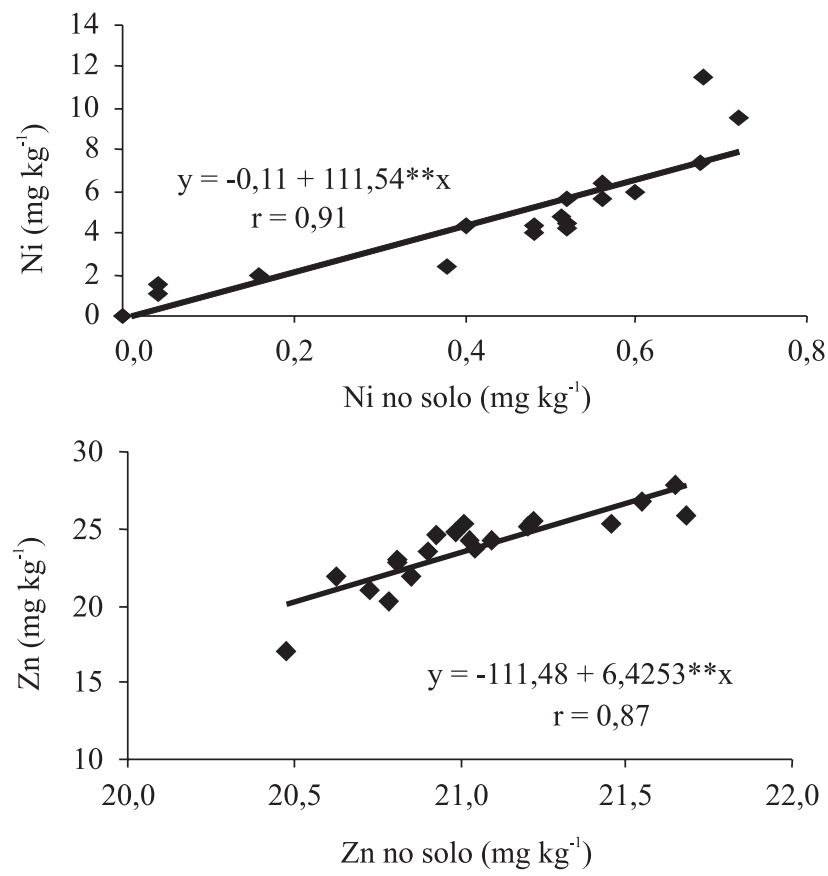

Figura 1. Concentração de $\mathrm{Cu}, \mathrm{Ni}, \mathrm{Pb}$ e Zn em folhas de bananeira (Y) em função dos teores extraídos por solução de ácidos orgânicos, em Latossolo Amarelo distrófico tratado com lodo de esgoto (X). * e **Significativo a 5\% e a 1\% pelo teste F, respectivamente. 
permitindo o acúmulo de metais pesados na solução extratora, apesar da baixa atividade desses elementos na solução do solo.

$\mathrm{O}$ fato de o método estar baseado em reações que ocorrem na rizosfera foi importante na obtenção dos resultados positivos deste trabalho. O extrator utilizado é composto por ácidos orgânicos presentes na rizosfera, considerados fitodisponibilizadores de metais pesados em solos tratados com lodo de esgoto (Mench \& Martin, 1991). Com isso, a extração em laboratório assemelhase mais com a que ocorre na rizosfera.

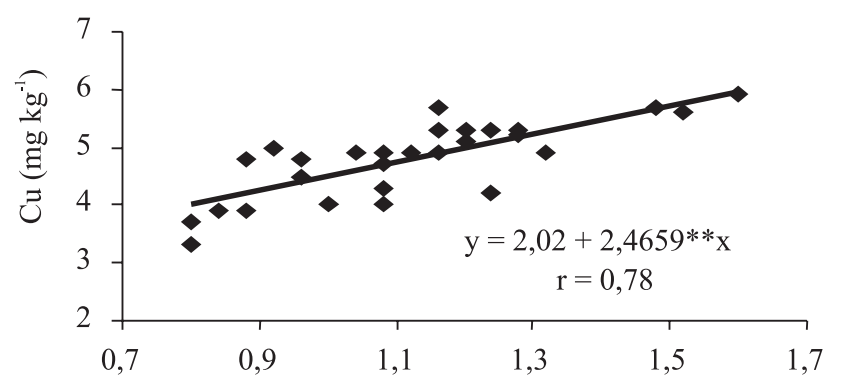

$\mathrm{Cu}$ no solo $\left(\mathrm{mg} \mathrm{kg}^{-1}\right)$
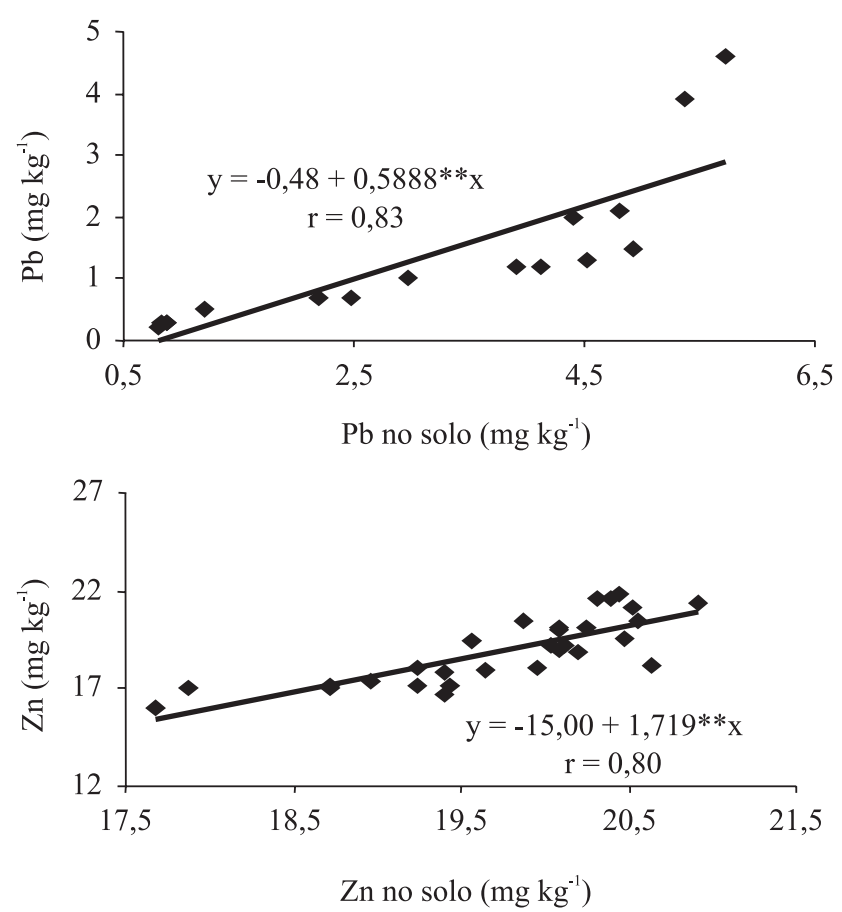

Figura 2. Concentração de $\mathrm{Cu}, \mathrm{Ni}, \mathrm{Pb}$ e $\mathrm{Zn}$ em folhas de pupunheira (Y) em função dos teores extraídos por solução de ácidos orgânicos, em Neossolo Quartzarêmico tratado com lodo de esgoto $(\mathrm{X})$. **Significativo a $1 \%$ pelo teste $\mathrm{F}$.
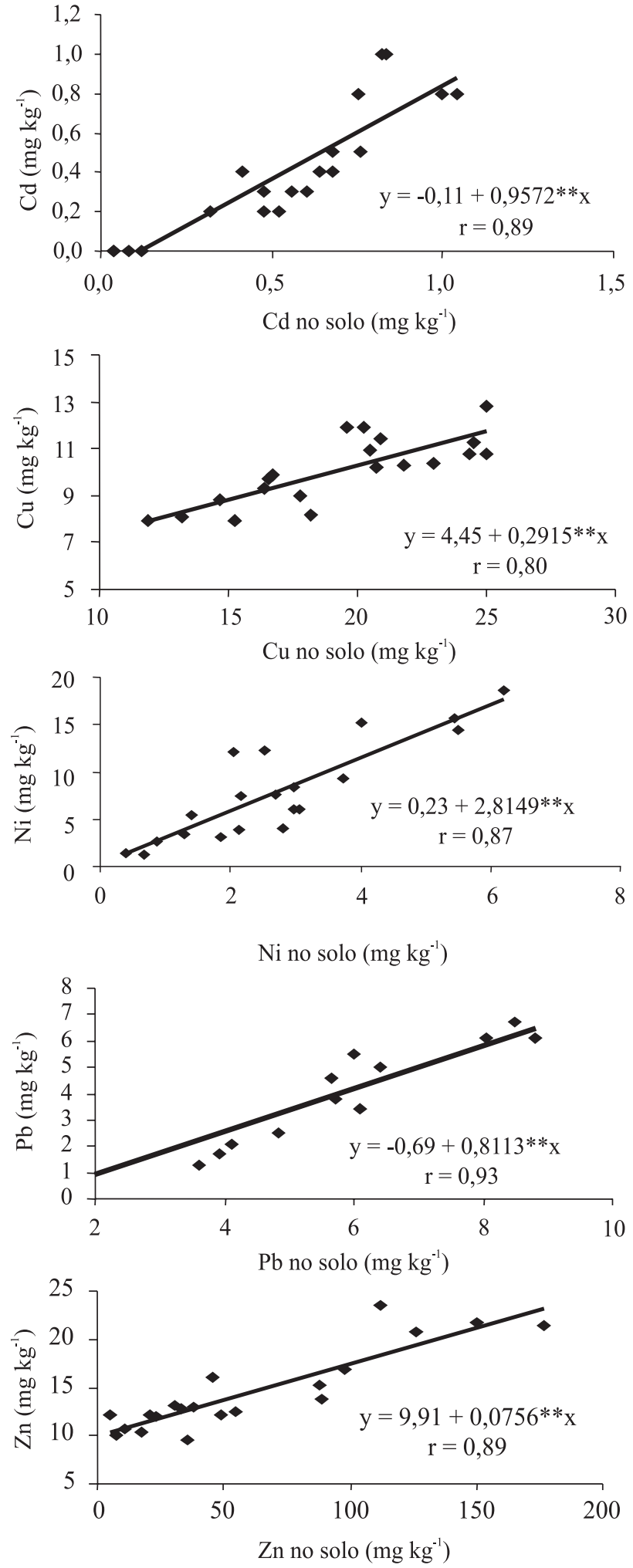

Figura 3. Concentração de $\mathrm{Cu}, \mathrm{Ni}, \mathrm{Pb}$ e $\mathrm{Zn}$ em folhas de café (Y) em função dos teores extraídos por solução de ácidos orgânicos, em Latossolo Vermelho distrófico tratado com lodo de esgoto $(\mathrm{X})$. **Significativo a $1 \%$ pelo teste $\mathrm{F}$. 


\section{Conclusão}

A solução extratora composta por ácidos orgânicos encontrados na rizosfera é eficiente em avaliar a disponibilidade de metais pesados.

\section{Agradecimentos}

À Fapesp, pelos recursos concedidos.

\section{Referências}

ABREU, C.A. de; ABREU, M.F. de; RAIJ, B. van; SANTOS, W.R. Comparação de métodos de análise para avaliar a disponibilidade de metais pesados em solos. Revista Brasileira de Ciência do Solo, v.19, p.463-468, 1995.

ANDRADE, C.A.; MATTIAZZO, M.E. Nitratos e metais pesados no solo e nas árvores após aplicação de biossólido (lodo de esgoto) em plantações florestais de Eucalyptus grandis. Scientia Florestalis, v.58, p.59-72, 2000.

ANJOS, A.R.M.; MATTIAZZO, M.E. Extratores para Cd, Cu, Cr, $\mathrm{Mn}, \mathrm{Ni}, \mathrm{Pb}$ e Zn em Latossolos tratados com biossólidos e cultivados com milho. Scientia Agricola, v.58, p.337-344, 2001.

BATAGLIA, O.C.; RAIJ, B. van. Soluções extratoras na avaliação da fitodisponibilidade do zinco em solos. Revista Brasileira de Ciência do Solo, v.19, p.457-461, 1994.

BERTON, R.S. Riscos de contaminação do agroecossistema com metais pesados. In: BETTIOL, W.; CAMARGO, O.A. (Ed.). Impacto ambiental do uso agrícola do lodo de esgoto. Jaguariúna: Embrapa Meio Ambiente, 2000. p.259-268.

BERTONCINI, E.I. Comportamento de Cd, Cr, Cu, Ni e Zn em Latossolos sucessivamente tratados com biossólido: extração seqüencial, fitodisponibilidade e caracterização de substâncias húmicas. 2002. 195p. Tese (Doutorado) - Escola Superior de Agricultura Luiz de Queiroz, Piracicaba.

CAMARGO, O.A.; MONIZ, A.C.; JORGE, J.A.; VALADARES, J.M.A.S. Métodos de análise química, mineralógica e física de solos do Instituto Agronômico. Campinas: Instituto Agronômico, 1986. 94p. (Boletim Técnico, 106).

EATON, A.D.; CLESCERI, L.S.; GREENBERG, A.C. Standards methods for the examination of water and wastewater. $19^{\text {th }}$ ed. Washington: American Public Health Association, 1995. 1082p.
ESTADOS UNIDOS. Environmental Protection Agency. 40 CFRPart 503 final rules: standards for the use of sewage sludge. Washington, 1993. p.9387-9415. (Federal Register, 58).

KOO, B.J. Assessing bioavailability of metals in biosolid treated soils: root exudates and their effects on solubility of metals. 2001. 261p Thesis (Ph.D.) - University of California, Riverside.

LINDSAY, W.L.; NORWELL, W.A. Development of a DTPA soil test for zinc, iron, manganese and copper. Soil Science Society of America Journal, v.42, p.421-428, 1978.

MARSCHNER, H. Mineral nutrition of higher plants. London: Academic, 1995. 889p.

MATTIAZZO, M.E.; BERTON, R.S.; CRUZ, M.C.P. Disponibilidade e avaliação de metais pesados potencialmente tóxicos. In: FERREIRA, M.E. (Ed.). Micronutrientes e elementos tóxicos na agricultura. Jaboticabal: CNPq; Fapesp; Potafos, 2001. 599p.

MEHLICH, A. Mehlich 3 soil test extractant: a modification of Mehlich 2 extractant. Communications in Soil Science and Plant Analysis, v.15, p.1409-1416, 1984.

MENCH, M.; MARTIN, M. Mobilization of cadmium and other metals from two soils by root exudates of Zea mays L., Nicotiana tabacum L., and Nicotiana rustica L. Plant and Soil, v.132, p.187196, 1991.

NELSON, W.L.; MEHLICH, A.; WINTERS, E. The development, evaluation and use of soil test for phosphorus availability. Agronomy, v.4, p.153-188, 1953.

OLIVEIRA, F.C. Disposição de lodo de esgoto e composto de lixo urbano num Latossolo Vermelho Amarelo cultivado com cana-de-açúcar. 2000. 247p. Tese (Doutorado) - Escola Superior de Agricultura Luiz de Queiroz, Piracicaba.

PAGE, A.L.; MILLER, P.H.; KEENEY, D.F. Methods of soil analysis. $2^{\text {nd }}$ ed. Madison: Soils Science Society of America, 1982. 1159p.

PIRES, A.M.M. Ácidos orgânicos da rizosfera: aspectos qualitativos e quantitativos e fitodisponibilidade de metais pesados originários de biossólidos. 2003. 94p. Tese (Doutorado) - Escola Superior de Agricultura Luiz de Queiroz, Piracicaba.

RAIJ, B. van; QUAGGIO, J.A. Métodos de análise química de solo para fins de fertilidade. Campinas: Instituto Agronômico, 1983. 31p. (Boletim Técnico, 81).

URE, A.M. Methods of analysis for heavy metals in soil. In: ALLOWAY, B.J. (Ed.). Heavy metals in soils. London: Blackie Academic and Professional, 1995. 368p.

Recebido em 17 de novembro de 2003 e aprovado em 19 de março de 2004

Pesq. agropec. bras., Brasília, v.39, n.7, p.671-676, jul. 2004 